\title{
Clinical, Demographic and Treatment Characteristics of Pediatric Psoriasis: A Multicenter Study of 150 Patients
}

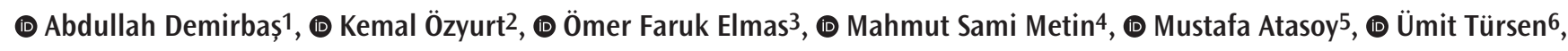 \\ (1) Asuman Kilitci7, (1) Torello Lotti8
}

1Department of Dermatology, Konya Numune State Hospital, Konya, Turkey

2Department of Dermatology, Kırșehir Ahi Evran University, Kırșehir, Turkey

3Department of Dermatology, Kırıkkale University, Kırıkkale, Turkey

${ }^{4}$ Department of Dermatology, Adana Kozan State Hospital, Adana, Turkey

${ }^{5}$ Department of Dermatology, Health Science University, Kayseri City Hospital, Kayseri, Turkey

${ }^{6}$ Department of Dermatology, Mersin University, Mersin, Turkey

7Department of Pathology, Kırșehir Ahi Evran University, Kırșehir, Turkey

8Department of Dermatology, Guglielmo Marconi University, Rome, Italy

\section{Abstract}

BACKGROUND/AIMS: Many studies have focused on the epidemiological features of adult and childhood psoriasis. However, only a few studies have been conducted to demonstrate the clinical and demographic characteristics of pediatric psoriasis in Turkey. This study aimed to determine clinical, demographic, and treatment characteristics of childhood psoriasis in a multicenter series.

MATERIALS and METHODS: This study was conducted in four different centers that are located in four cities of Turkey between June 2016 and June 2020. The demographic parameters, possible triggering factors (emotional stress, physical trauma, infection, and medication), and clinical characteristics (psoriasis type, psoriasis area severity index, involved areas, nail involvement, joint involvement, subjective symptoms, disease duration, last treatments and duration of use, and history of accompanying diseases) of pediatric patients with psoriasis were retrospectively analyzed.

RESULTS: A total of 150 patients from four different centers were enrolled in the study, of whom $71(47.30 \%)$ were males and 79 (52.70\%) were females, with a mean age of $13.71 \pm 4.2$ years (age range: 1-18 years). A family history of psoriasis was determined in 20 (13.33\%) patients. Possible triggering factors included emotional stress $(n=90,60 \%)$, physical trauma $(n=21,14 \%)$, infection $(n=14,9.33 \%)$, and medication $(n=1$, 1.67\%). The most common area of involvement was the trunk $(n=69,46 \%)$ followed by the scalp $(n=42,28 \%)$, hand $(n=20,13.33 \%)$, and face $(n=19,12.67 \%)$. The prevalence of clinical types was as follows: plaque $(n=125,83.33 \%)$, guttate $(n=10,6.67 \%)$, palmoplantar $(n=7,4.67 \%)$, inverse $(n=6,4 \%)$, and pustular $(n=2,1.33 \%)$ psoriasis. Nail and joint involvement were observed in $30(20 \%)$ and $15(10 \%)$ patients, respectively. The last treatments received included topical treatment $(n=101,67.33 \%)$, phototherapy $(n=23,15.33 \%)$, acitretin $(n=16,10.67 \%)$, methotrexate $(n=9,6 \%)$, and cyclosporine $(n=1,0.67 \%)$.

CONCLUSION: In our cohort, the clinical types and treatments used for childhood psoriasis were similar to those of other studies, but the rate of family history was lower, whereas the incidence of emotional stress was higher. Addressing the psychological impacts of psoriasis along with its physical aspects may provide better treatment outcomes.

Keywords: Nail, children, treatment, psoriasis

To cite this article: Demirbaş A, Özyurt K, Elmas ÖF, Metin MS, Atasoy M, Türsen Ü, Kilitci A, Lotti T. Clinical, Demographic and Treatment Characteristics of Pediatric Psoriasis: A Multicenter Study of 150 Patients. Cyprus J Med Sci 2021;6(Suppl 1):7-13

ORCID iDs of the authors: A.D. 0000-0002-3419-9084; K.Ö. 0000-0002-6913-8310; Ö.F.E. 0000-0002-5474-6508; M.S.M. 0000-0002-5099-8521; M.A. 0000-0003-1904-9878; Ü.T. 0000-0002-5807-6759; A.K. 0000-0002-5489-2222; T.L. 0000-0003-0840-1936. 


\section{INTRODUCTION}

Psoriasis is a chronic inflammatory skin disease that is characterized by sharply circumscribed erythematous scaly plaques. Polygenic predisposition and environmental triggers play essential roles in etiopathogenesis. ${ }^{1}$ Psoriasis has been reported to constitute $3.8 \%$ of all outpatient clinic visits in childhood and adolescence. ${ }^{2}$ Recent epidemiological studies have shown that the prevalence of childhood and adolescent psoriasis varies between $0 \%$ and $1.37 \%{ }^{3}$ The age of onset for pediatric psoriasis is unknown; however, psoriasis occurs before 10 years of age in $10 \%$ of the affected children and before 2 years in $2 \%{ }^{4}$ Many studies focused on the epidemiological features of adult and childhood psoriasis. However, only a few studies have been conducted to demonstrate the clinical and demographic characteristics of pediatric psoriasis in Turkey. ${ }^{2,5-10}$ This multicenter cohort study aimed to reveal the clinical and demographic features of pediatric psoriasis in Turkey.

\section{MATERIALS and METHODS}

\section{Patients}

This study was conducted in four different centers that are located in four cities of Turkey between June 2016 and June 2020 and included patients under 18 years old who were diagnosed with psoriasis. The relevant data were retrieved from a psoriasis registry system (PSORTAKSIS) integrated into the hospital electronic record system. ${ }^{11}$

\section{Diagnosis}

The diagnosis was principally made based on clinical features, but in cases where clinical findings were not typical, the diagnosis was histopathologically confirmed. The histopathological criteria for psoriasis were as follows: parakeratosis; hyperkeratosis; absence/reduction of the granular cell layer; rete ridge elongation; neutrophilic aggregates within the epidermis and dermis (microabscesses of Munro and pustules of Kogoj); dilatation of superficial dermal capillaries; and perivascular lymphocyte infiltration (Figure 1). Cases with suspicion in the diagnosis despite histopathological examination were excluded.

\section{Parameters}

The parameters that were retrospectively analyzed were as follows; 1) epidemiological data: age, gender, weight, height, body mass index (BMI), family history, and possible triggering factors (emotional stress, physical trauma, infection, and medication); 2) clinical features: psoriasis type, psoriasis area severity index (PASI), areas of involvement, nail involvement, joint involvement, subjective symptoms, disease duration, last medication and duration of use, and history of accompanying disease. The presence of at least one of the following changes observed by parents was considered an indicator of emotional stress: excessive worries, acting irritable or moody, withdrawing from activities that used to give pleasure, complaining more than usual about the school, and showing surprising fearful reactions.

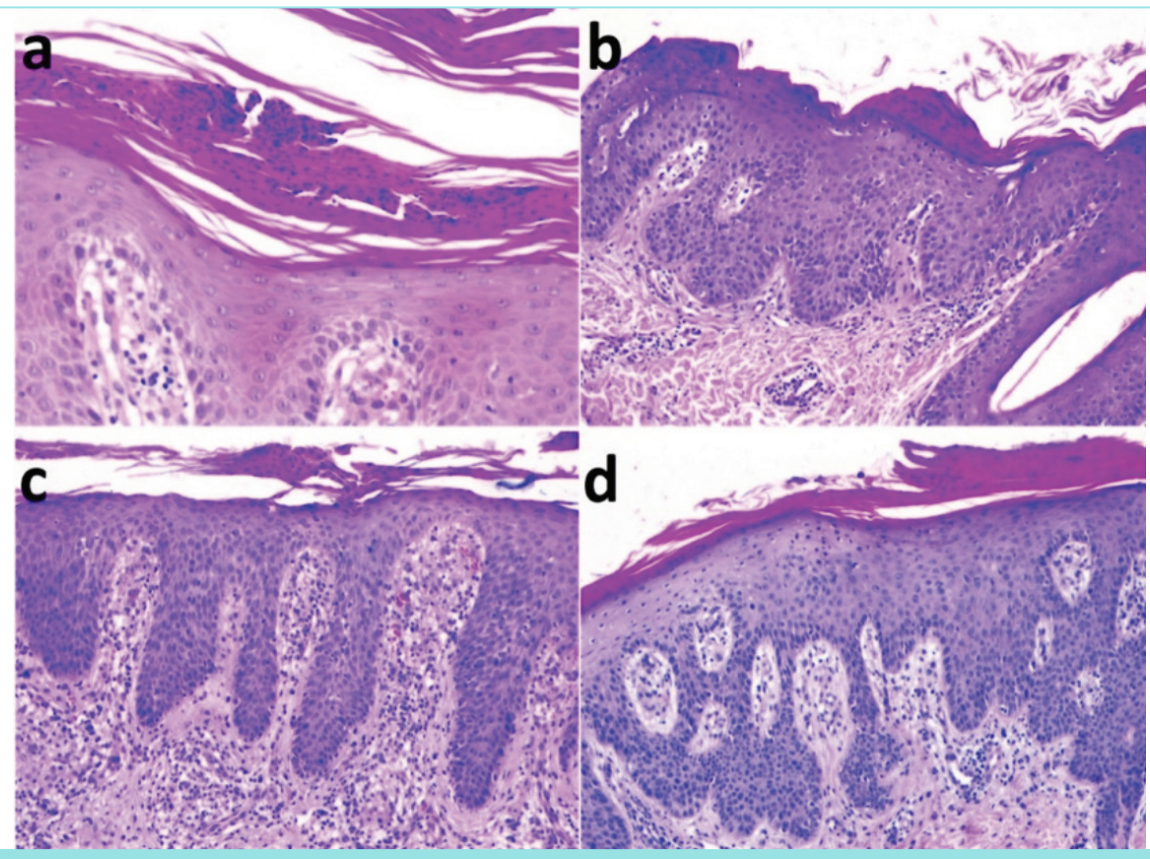

Figure 1. Histopathological microphotographs of four pediatric patients diagnosed with psoriasis vulgaris. Biopsies demonstrate microabscesses of Munro (a, b) (H\&E, $\times 200 ; \mathrm{H} \& E, \times 100)$, parakeratosis, hyperkeratosis, hypogranulosis, elongation of the rete ridges, and dermal perivascular lymphocyte infiltration (c, d) (H\&E, ×100; H\&E, ×100).

H\&E: Hematoxylin and eosin stain. 


\section{Statistical Analysis}

The data obtained were analyzed using International Business Machines Statistical Package for the Social Sciences version 23 (SPSS Inc., Chicago, IL, USA) package program. Descriptive statistics were used, with categorical variables that are summarized using numbers and percentages and continuous variables using mean, standard deviation, minimum, and maximum. The normality of distribution was analyzed using the Shapiro-Wilk test. Relationships between variables were analyzed via the chi-square test, the Spearman correlation test, the logistic regression, and the multiple logistic regression. The findings were evaluated at a $95 \%$ confidence interval and $5 \%$ significance level. A $p$-value of $<0.05$ was considered statistically significant.

\section{Ethics Approval}

All the procedures followed the Helsinki declaration, and the study was approved by the local institutional review board (decision date and number: 2020-09/78).

\section{RESULTS}

A total of 150 patients from four different centers were enrolled in the study, of whom $71(47.30 \%)$ were males (mean age: 12.74 years) and 79 (52.70\%) were females (mean age: 14.57 years). The boy/girl ratio was $0.89 / 1$. The ages of patients ranged from 1 to 18 years with a mean age of $13.71 \pm 4.2$ years. The mean weight, height, and BMI were 47.44 (17.98) kg (range: 9-90), 1.5 (0.19) (range: 0.88-1.83) meters, and 20.15 (4.17) (range: $5.91-33.46) \mathrm{kg} / \mathrm{m}^{2}$, respectively. The mean disease duration was 3.65 (3.84) (1-34) months and the mean PASI score was 1.85 (2.29) (0-19). All clinical and demographic features of patients are shown in Table 1. Twenty patients (13.33\%) had a family history of psoriasis. Possible triggering factors included emotional stress $(n=90,60 \%)$, physical trauma $(n=21,14 \%)$, infection $(n=14,9.33 \%)$, and medication $(n=1,1.67 \%)$. The most common areas of involvement were the trunk $(n=69,46$ $\%)$ followed by the scalp $(n=42,28 \%)$, hand $(n=20,13.33 \%)$, and face $(n=19,12.67 \%)$. The prevalence of clinical types was as follows: plaque ( $n=125,83.33 \%)$, guttate $(n=10,6.67 \%)$, palmoplantar $(n=7,4.67 \%)$, inverse $(n=6,4 \%)$, and pustular $(\mathrm{n}=2,1.33 \%)$ psoriasis. Nail involvement was observed in $30(20 \%)$ patients including pitting $(n=16)$, subungual hyperkeratosis $(n=5)$, leukonychia $(n=5)$, onycholysis $(n=2)$, oil spot $(n=1)$, and discoloration $(n=1)$. Fifteen patients $(10 \%)$ showed joint involvement. Comorbidities included aortic stenosis $(n=1)$, diabetes mellitus $(n=1)$, familial Mediterranean fever $(n=1)$, chronic renal failure $(n=1)$, Henoch Schoenlein purpura $(n=1)$, liver cirrhosis $(n=1)$, and hypothyroidism. As treatment, $101(67.33 \%)$ patients were on topical, 23 (15.33\%) on phototherapy, 16 (10.67\%) on acitretin, 9 (6\%) on methotrexate, and $1(0.67 \%)$ on cyclosporine. The mean duration of the last treatment received was 4.67 (5.24) months. No statistically significant difference was found between any parameters in comprehensive statistical analysis.

\section{DISCUSSION}

Psoriasis is a polygenic and multifactorial papulosquamous disease, which is estimated to affect approximately 1\%-3\% of the population. ${ }^{1,12}$ The epidemiological data on pediatric psoriasis are limited. The prevalence of pediatric psoriasis has been reported in a range of $0.7 \%$ to $3.8 \%$ in different studies, and several studies have reported a mild female dominance. ${ }^{5,7,10,13-16}$ Similarly, our cohort also showed a mild female dominance (female/male: 1.11/1).

The etiopathogenesis of psoriasis is not fully known; however, evidence on the etiopathogenetic role of genetic factors has recently strengthened. The relevant literature has reported different rates of family history in psoriasis, varying from $4.5 \%$ to $89 \%,{ }^{6,7,9,10}$ Our study revealed a lower rate of family history than the majority of the reported rates in previous studies. Kumar et al. ${ }^{6}$ found the rate of family history as $4.5 \%$ and suggested that this low rate is related to the single center-limited design of their study. The low rate of family history in our multicenter series may indicate that the role of environmental factors in the etiopathogenesis of pediatric psoriasis is stronger than known. Contrarily, the low rate of family history in our series may be associated with the ignorance of family members concerning the presence of the disease. Additionally, the actual absence of the disease in family members at the time of diagnosis may have subsequently occurred. ${ }^{17}$ Environmental factors, including smoking, alcohol, emotional stress, climate, trauma, medicines, and infections, have played roles in the pathogenesis of psoriasis and are considered triggering factors for its emergence. ${ }^{18-20}$ Triggering factors play a more prominent role in pediatric cases compared to those of adults.,5, $14,17,18,20$ Studies have suggested that $30 \%-40 \%$ of cases are linked with emotional stress. ${ }^{19}$ Our study revealed that $60 \%$ of patients had emotional stress, whereas a history of physical trauma, infection, and medication was present in $14 \%, 9.33 \%$, and $1.67 \%$ of patients, respectively. Psoriasis affects the social and personal lives of patients, reduces the quality of life, and causes anxiety. Myths that psoriasis is a contagious disease stigmatize and exclude patients from social lives and schools. ${ }^{21}$ The high incidence of emotional stress that is observed in our series may be associated with these factors. Contrarily, our study results may support the role of the brain-skin axis in the pathogenesis of psoriasis.

Pediatric psoriasis may present with various clinical types, such as plaque, guttate, pustular, erythrodermic, inverse, palmoplantar plaque, palmoplantar pustular, and sebopsoriasis. These clinical types may show different 


\begin{tabular}{|c|c|c|}
\hline & $\begin{array}{l}\text { Number of patients } \\
(n=150)\end{array}$ & Percentage (\%) \\
\hline Female & 79 & 52.70 \\
\hline Male & 71 & 47.30 \\
\hline Age (mean $\pm S D$, min-max) & \multicolumn{2}{|l|}{$13.71 \pm 4.2(1-18)$} \\
\hline Weight (mean $\pm S D$, min-max) & \multicolumn{2}{|l|}{$47.44 \pm 17.98(9-90)$} \\
\hline Height (mean \pm SD, min-max) & \multicolumn{2}{|l|}{$1.5 \pm 0.19(0.88-1.83)$} \\
\hline $\mathrm{BMI} \dagger($ mean \pm SD, min-max) & \multicolumn{2}{|l|}{$20.06 \pm 4.17(5.91-33.46)$} \\
\hline Family history positivity & 20 & 13.33 \\
\hline Clinical types (n) & $\begin{array}{l}\text { Plaque (125) } \\
\text { Guttate (10) } \\
\text { Palmoplantar (7) } \\
\text { Inverse (6) } \\
\text { Pustular (2) }\end{array}$ & $\begin{array}{l}83.33 \\
6.67 \\
4.67 \\
4 \\
1.33\end{array}$ \\
\hline Localization (n) & $\begin{array}{l}\text { Trunk (69) } \\
\text { Scalp (42) } \\
\text { Hand (20) } \\
\text { Face (19) }\end{array}$ & $\begin{array}{l}46 \\
28 \\
13.33 \\
12.67\end{array}$ \\
\hline Disease duration (mean \pm SD, min-max) & \multicolumn{2}{|l|}{$3.65 \pm 3.84(1-34)$} \\
\hline Nail involvement (n) & $\begin{array}{l}\text { Pitting (16) } \\
\text { Subungual hyperkeratosis (5) } \\
\text { Leukonychia (5) } \\
\text { Onycholysis (2) } \\
\text { Oil spot (1) } \\
\text { Discoloration (1) }\end{array}$ & $\begin{array}{l}10.66 \\
3.33 \\
3.33 \\
1.33 \\
0.67 \\
0.67\end{array}$ \\
\hline Joint involvement & 15 & 10 \\
\hline Accompanying diseases (n) & $\begin{array}{l}\text { Aortic stenosis (1) } \\
\text { Diabetes Mellitus (1) } \\
\operatorname{FMF}^{\ddagger}(1) \\
\operatorname{CRF}^{\S}(1) \\
\operatorname{HSP}^{\ddagger}(1) \\
\text { Cirrhosis (1) } \\
\text { Hypothyroidism (1) }\end{array}$ & $\begin{array}{l}0.67 \\
0.67 \\
0.67 \\
0.67 \\
0.67 \\
0.67 \\
0.67\end{array}$ \\
\hline Triggering Factors (n) & $\begin{array}{l}\text { Stress (90) } \\
\text { Trauma (21) } \\
\text { Infection (14) } \\
\text { Medicine (1) }\end{array}$ & $\begin{array}{l}60.00 \\
14.00 \\
9.33 \\
1.67\end{array}$ \\
\hline Last treatment $(\mathrm{n})$ & $\begin{array}{l}\text { Topical therapy (101) } \\
\text { Phototherapy (23) } \\
\text { Acitretin (16) } \\
\text { Methotrexate (9) } \\
\text { Cyclosporine (1) }\end{array}$ & $\begin{array}{l}67.33 \\
15.33 \\
10.67 \\
6 \\
0.67\end{array}$ \\
\hline $\begin{array}{l}\text { Duration of last treatment } \\
\text { (mean } \pm S D, \text { min-max) }\end{array}$ & \multicolumn{2}{|l|}{$4.67 \pm 5.24(1-19)$} \\
\hline PASI Score\# (mean \pm SD, min-max) & \multicolumn{2}{|l|}{$1.85 \pm 2.29(0-19)$} \\
\hline
\end{tabular}


prevalence in different ethnic groups. Epidemiological studies have shown that the most common type of psoriasis in childhood is plaque type, as it is in adults. ${ }^{22}$ A series of pediatric psoriasis $(n=277)$ reported by Fan et al. ${ }^{7}$ revealed that the most common type was plaque psoriasis (68.6\%) followed by guttate (28.9\%), arthropathic psoriasis $(2.9 \%)$, erythrodermic (1.4\%), and pustular psoriasis (1.1\%). Another study by Moustou et al. ${ }^{8}$ revealed that $82.1 \%$ of 842 children had plaque-type psoriasis, whereas $20.2 \%$ and $7.5 \%$ had inverse and guttate psoriasis, respectively. Another study that involved 280 patients with pediatric psoriasis revealed that $68 \%$ had plaque type, whereas $12.5 \%$ and $11 \%$ had guttate and palmoplantar types, respectively. ${ }^{23}$ Our study revealed that the most common type of psoriasis was plaque type $(n=125$, $83.33 \%)$, followed by guttate ( $n=10,6.67 \%)$, palmoplantar $(n=7,4.67 \%)$, inverse $(n=6,4 \%)$, and pustular $(n=2,1.33 \%)$ psoriasis. Erythrodermic psoriasis and arthropathic psoriasis are rare in childhood. ${ }^{24-26}$ In our series, psoriatic arthritis was accompanied by other clinical types in $10 \%$ of patients, whereas none had erythrodermic psoriasis.

A series of 207 cases that compared the clinical characteristics of European and Asian children with psoriasis revealed that the scalp was the most common location. ${ }^{27}$ However, Fan et al. ${ }^{7}$ reported that the most common locations were leg extensors, arms, and scalp, whereas Kwon et al. $^{16}$ found that the most common area of involvement was the trunk. In our series, the lesions were mostly located in the trunk $(n=69,46 \%)$ followed by the scalp $(n=42,28 \%)$, hand $(n=20,13.33 \%)$, and face $(n=19$, $12.67 \%)$.

Nail involvement can be observed in $7 \%-40 \%$ of patients with pediatric psoriasis., ${ }^{5,18}$ Relevant literature reported that the most commonly reported nail finding is pitting. Subungual hyperkeratosis, onycholysis, oil spot, and longitudinal streaking are also relatively common. ${ }^{7,18,25,26}$ In our series, $10.66 \%$ of patients had nail pitting, whereas other findings included subungual hyperkeratosis, leukonychia, onycholysis, oil spot, and discoloration.

Recent studies showed that psoriasis is a chronic systemic inflammatory disease rather than a skin-limited condition. ${ }^{28}$ Patients with psoriasis, compared to the healthy population, have a higher incidence of hyperlipidemia, obesity, hypertension, diabetes mellitus, ischemic heart disease, rheumatoid arthritis, Crohn's disease, and ulcerative colitis. ${ }^{19,29}$ Our series revealed that seven patients had accompanying disorders including aortic stenosis $(n=1)$, diabetes mellitus $(n=1)$, Familial Mediterranean Fever $(n=1)$, chronic renal failure $(n=1)$, Henoch Schoenlein purpura $(n=1)$, liver cirrhosis $(n=1)$, and hypothyroidism. The low number of patients with comorbidities in our series makes it difficult to understand the causal relationship between these comorbidities and psoriasis.

No standardized evidence-based treatment protocols are available for pediatric psoriasis, mainly due to the paucity of randomized and controlled studies. However, the vast majority of studies consider topical agents as the first step in mild to moderate psoriasis. ${ }^{18,24,29}$ Phototherapy, particularly narrowband UV-B, maybe the first option for patients who are unresponsive to topical therapies and those with moderate to severe psoriasis. ${ }^{29,30}$ The adverse effects profile and the lack of large-scale studies that are focused on childhood psoriasis limit the use of systemic drugs. Our series revealed that the last treatments received included topical treatment $(n=101,67.33 \%)$, phototherapy $(n=23,15.33 \%)$, acitretin $(n=16,10.67 \%)$, methotrexate $(n=9$, $6 \%)$, and cyclosporine $(n=1,0.67 \%)$. The main limitations of our study include its retrospective nature and the relatively small number of included patients, which could have biased statistical analyses.

To sum up, our series showed similar results regarding the clinical types and treatments used for childhood psoriasis (Table 2). However, comparing the previous studies, the rate of family history was found to be lower, whereas the frequency of emotional stress was higher. We believe that addressing the psychological impact of psoriasis along with its physical aspects may provide better treatment outcomes.

\section{Main Points}

- In a multicenter series, we tried to evaluate the clinical, demographic, and treatment features of childhood psoriasis.

- A total of 150 patients from four different centers were enrolled in the study.

- This cohort is the largest recently conducted the study in our country.

- In our cohort, the clinical types and treatments used for childhood psoriasis were similar to those of other studies, but the rate of family history was lower, whereas the incidence of emotional stress was higher. Addressing the psychological impacts of psoriasis along with its physical aspects may provide better treatment outcomes. 


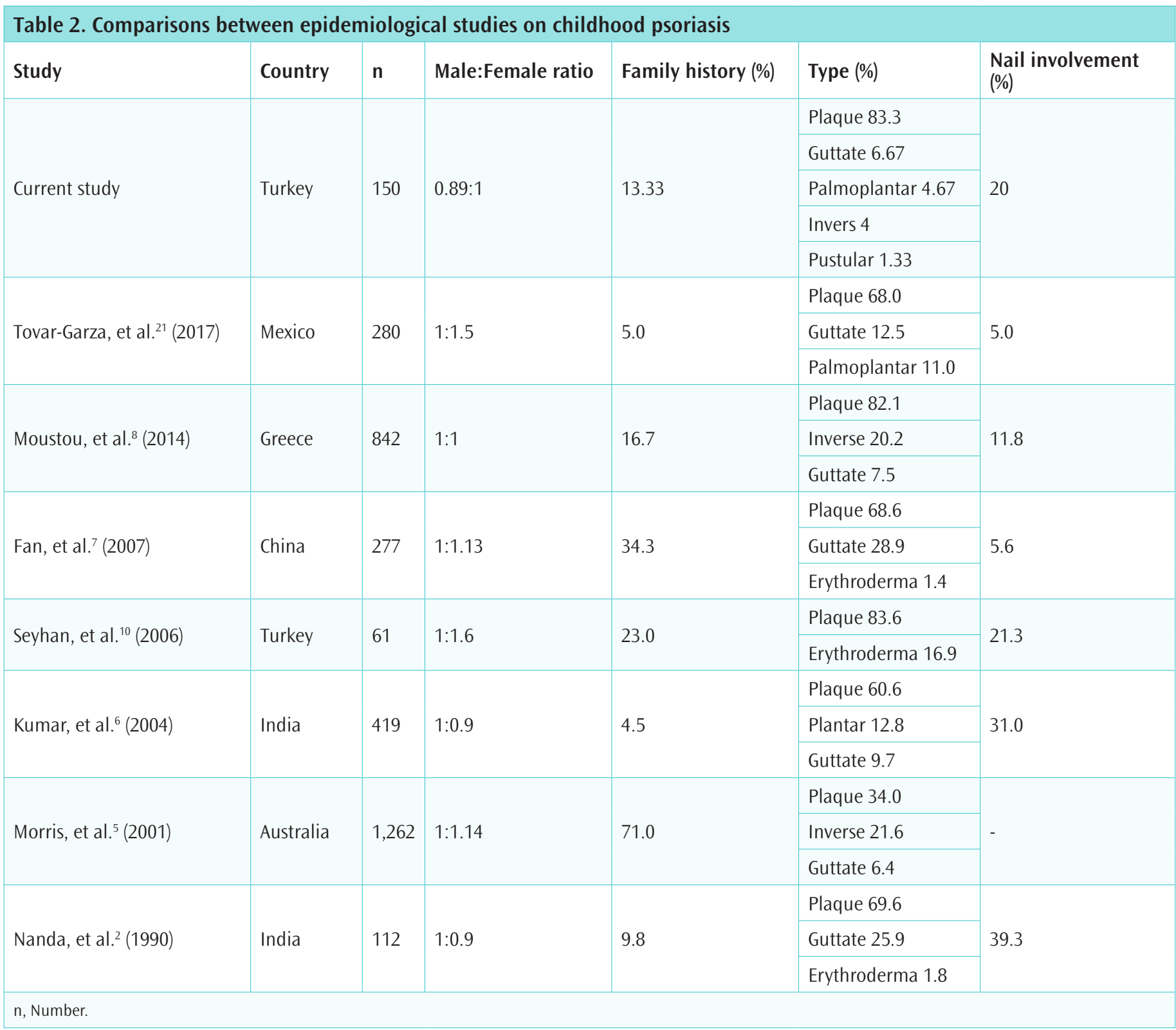

\section{ETHICS}

Ethics Committee Approval: All the procedures followed the Helsinki declaration, and the study was approved by the Clinical Research Ethics Committee of Kırşehir Ahi Evran University Faculty of Medicine (decision date and number: 2020-09/78).

Informed Consent: Retrospective study.

Peer-review: Externally peer-reviewed.

\section{Authorship Contributions}

Conception: Ö.F.E., Design: A.K., Supervision: K.Ö., Ü.E., Data Collection and/or Processing: K.Ö., M.S.M., Analysis and/or Interpretation: A.D., Literature Review: Ö.F.E., Writing: A.D.,
Critical Review: M.A., T.L.

\section{DISCLOSURES}

Financial Disclosure: The author declared no financial support for this study.

Conflict of Interest: The authors declared no conflict of interest.

\section{REFERENCES}

1. Relvas M, Torres T. Pediatric psoriasis. Am J Clin Dermatol. 2017;18:797-811.

2. Nanda A, Kaur S, Kaur I, et al. Childhood psoriasis: an epidemiologic survey of 112 patients. Pediatr Dermatol. 1990;7:19-21.

3. Michalek IM, Loring B, John SM. A systematic review of worldwide epidemiology of psoriasis. J Eur Acad Dermatol Venereol. 2017;31:205-212. 
4. Burden AD. Management of psoriasis in childhood. Clin Exp Dermatol. 1999;24:341-345.

5. Morris A, Rogers M, Fischer G, et al. Childhood psoriasis: a clinical review of 1262 cases. Pediatr Dermatol. 2001;18:188-98.

6. Kumar B, Jain R, Sandhu K, et al. Epidemiology of childhood psoriasis: a study of 419 patients from northern India. Int J Dermatol. 2004;43:654-658.

7. Fan X, Xiao FL, Yang S, et al. Childhood psoriasis: a study of 277 patients from China. J Eur Acad Dermatol Venereol. 2007;21:762-765.

8. Moustou AE, Kakourou T, Masouri S, et al. Childhood and adolescent psoriasis in Greece: a retrospective analysis of 842 patients. Int J Dermatol. 2014; 53:1447-1453.

9. Bükülmez G, Ersoy S, Atakan N, et al. Çocukluk çağı psoriazisinin klinik özellikleri: 117 vakalık retrospektif bir çalıșma. Türkderm. 2001;35:43-5.

10. Seyhan M, Coșkun BK, Sağlam H, Ozcan H, Karincaoğlu Y. Psoriasis in childhood and adolescence: evaluation of demographic and clinical features. Pediatr Int. 2006;48:525-530.

11. Özyurt K, AvCI A, Ertaş R, et al. PSORTAKSIS: A new psoriasis patient registry system used in dermatology clinic of Kayseri Health Training and Research Center. Turk J Dermatol. 2018;12:23-27.

12. Huerta C, Rivero E, Rodríguez LA. Incidence and risk factors for psoriasis in the general population. Arch Dermatol. 2007;143:1559-1565.

13. Gelfand JM, Weinstein R, Porter SB, Neimann AL, Berlin JA, Margolis DJ. Prevalence and treatment of psoriasis in the United Kingdom: a populationbased study. Arch Dermatol. 2005;141:1537-1541.

14. Augustin M, Glaeske G, Radtke MA, Christophers E, Reich K, Schäfer I. Epidemiology and comorbidity of psoriasis in children. $\mathrm{Br} /$ Dermatol. 2010;162:633-636.

15. Tollefson MM, Crowson CS, McEvoy MT, Maradit Kremers H. Incidence of psoriasis in children: a population-based study. J Am Acad Dermatol. 2010;62:979-987.

16. Kwon HH, Na SJ, Jo SJ, Youn JI. Epidemiology and clinical features of pediatric psoriasis in tertiary referral psoriasis clinic. J Dermatol. 2012;39:260-264.
17. Henseler T. The genetics of psoriasis. J Am Acad Dermatol. 1997;37:S1-11.

18. Silverberg NB. Pediatric psoriasis: an update. Ther Clin Risk Manag. 2009;5:849-856.

19. Ozden MG, Tekin NS, Gürer MA, et al. Environmental risk factors in pediatric psoriasis: a multicenter case-control study. Pediatr Dermatol. 2011;28:306312.

20. Dogra S, Kaur I. Childhood psoriasis. Indian I Dermatol Venereol Leprol. 2010;76:357-365.

21. Sahi FM, Masood A, Danawar NA, Mekaiel A, Malik BH. Association between psoriasis and depression: a traditional review. Cureus. 2020;12:e9708.

22. Chandran NS, Gao F, Goon AT, Chong WS, Giam YC, Theng CT. Clinical characteristics of childhood psoriasis in a multi-ethnic Asian population. J Dermatol. 2012;39:278-279.

23. Tovar-Garza A, Meza-Resendiz M, Guevara-Gutiérrez E, Barrientos-García JG, Tlacuilo-Parra A. Psoriasis in children and adolescents: epidemiological study of 280 patients from Mexico. Rev Invest Clin. 2017;69:47-50.

24. Sticherling M, Augustin M, Boehncke WH, et al. Therapy of psoriasis in childhood and adolescence - a German expert consensus. J Dtsch Dermatol Ges. 2011;9:815-823.

25. Stefanaki C, Lagogianni E, Kontochristopoulos G, et al. Psoriasis in children: a retrospective analysis. J Eur Acad Dermatol Venereol. 2011;25:417-421.

26. Dhar S, Banerjee R, Agrawal N, Chatterjee S, Malakar R. Psoriasis in children: an insight. Indian J Dermatol. 2011;56:262-265.

27. Chiam LY, de Jager ME, Giam YC, de Jong EM, van de Kerkhof PC, Seyger MM. Juvenile psoriasis in European and Asian children: similarities and differences. BrJ Dermatol. 2011;164:1101-1103.

28. Grozdev I, Korman N, Tsankov N. Psoriasis as a systemic disease. Clin Dermatol. 2014;32:343-350.

29. Megna M, Napolitano M, Balato A, et al. Psoriasis in children: a review. Curr Pediatr Rev. 2015;11:10-26.

30. Jain VK, Aggarwal K, Jain K, Bansal A. Narrow-band UV-B phototherapy in childhood psoriasis. Int J Dermatol. 2007;46:320-322. 